\title{
Contribution of Vascular NAD(P)H Oxidase to Endothelial Dysfunction in Heart Failure and the Therapeutic Effects of HMG-CoA Reductase Inhibitor
}

\author{
Tomoyuki Takayama, MD; Atsuyuki Wada, MD; Takayoshi Tsutamoto, MD; Masato Ohnishi, MD; \\ Masanori Fujii, MD; Takahiro Isono, PhD*; Minoru Horie, MD
}

\begin{abstract}
Background The vascular NAD $(\mathrm{P}) \mathrm{H}$ oxidase-derived superoxide anion $\left(\mathrm{O}_{2}{ }^{-}\right)$plays a crucial role in the pathological progression of hypertension and atherosclerosis, and HMG-CoA reductase inhibitors (statins) have vascular antioxidant effects. However, it is unclear whether the vascular NAD(P)H oxidase is involved in the endothelial dysfunction of congestive heart failure (CHF) and whether HMG-CoA reductase inhibitors (statins) exert their vasoprotective effects in CHF. The present study examined both the involvement of vascular $\mathrm{NAD}(\mathrm{P}) \mathrm{H}$ oxidase in endothelial dysfunction in dogs with tachycardia-induced CHF and the therapeutic effect of a statin (pitavastatin).

Methods and Results Femoral blood flow (FBF) responses to acetylcholine was significantly impaired in the CHF group, but were improved by pitavastatin. Vascular $\mathrm{O}_{2}^{-}$production, $\mathrm{NAD}(\mathrm{P}) \mathrm{H}$ oxidase activity and Nox4 and $\mathrm{p} 47$ phox expression were significantly elevated in CHF compared with the normal group. The elevated $\mathrm{O}_{2}{ }^{-}$ production in the CHF group was suppressed by the $\mathrm{NAD}(\mathrm{P}) \mathrm{H}$ oxidase inhibitor, apocynin, to the normal level. In contrast, neither the gene expression nor the activity of endothelial nitric oxide synthase (eNOS) differed significantly between the normal and CHF groups. However, pitavastatin significantly suppressed $\mathrm{O}_{2}{ }^{-}$production, $\mathrm{NAD}(\mathrm{P}) \mathrm{H}$ oxidase activity and Nox4 and p47phox expression and increased eNOS expression and activity compared with the CHF group.

Conclusions The activated vascular $\mathrm{NAD}(\mathrm{P}) \mathrm{H}$ oxidase contributes to endothelial dysfunction in CHF, which was partly improved by pitavastatin via its inhibition of NAD(P)H oxidase. (Circ J 2004; 68: 1067-1075)
\end{abstract}

Key Words: Congestive heart failure; Endothelial dysfunction; NAD(P)H oxidase; Pitavastatin

I n patients with congestive heart failure (CHF), endothelium-dependent vasodilation is significantly attenuated in both the large arteries and the microvessels of the peripheral circulation, ${ }^{1,2}$ which limits skeletal muscle blood flow and correlates with the severity of symptoms, and improvement of the endothelial dysfunction is an important target in the treatment of CHF. The main characteristic of vascular endothelial dysfunction is reduced bioavailability of nitric oxide (NO); ${ }^{3}$ however, even if the expression of both endothelial nitric oxide synthase (eNOS) mRNA and soluble guanylate cyclase is relatively increased in CHF, endothelium-dependent vasorelaxation is diminished as a result of the significant elevation of superoxide anion $\left(\mathrm{O}_{2}{ }^{-}\right)$production because $\mathrm{O}_{2}{ }^{-}$rapidly scavenges $\mathrm{NO}$ and reduces the bioavailability of $\mathrm{NO}^{4}$ Oxidative stress plays a pivotal role in the alteration of endothelial function in $\mathrm{CHF}_{4}^{4-6}$

There are several sources of $\mathrm{O}_{2}^{-}$production within vessels, but $\mathrm{NAD}(\mathrm{P}) \mathrm{H}$ oxidase is present in vascular smooth muscle cells ${ }^{7}$ and endothelial cells ${ }^{8}$ and this enzyme

(Received May 18, 2004; revised manuscript received August 16, 2004; accepted August 30, 2004)

Department of Cardiovascular and Respiratory Medicine and $*$ Central Research Laboratory, Shiga University of Medical Science, Otsu, Japan

Mailing address: Atsuyuki Wada, MD, PhD, Department of Cardiovascular and Respiratory Medicine, Shiga University of Medical Science, Tsukinowa, Seta, Otsu 520-2192, Japan. E-mail: wada@ belle.shiga-med.ac.jp generates $\mathrm{O}_{2}{ }^{-}$through the assembly of a multi-subunit protein complex. Angiotensin II stimulates $\mathrm{O}_{2}-$ production via $\mathrm{NAD}(\mathrm{P}) \mathrm{H}$ oxidase located within the vascular wall ${ }^{7,9}$ and it has been shown that increased enzyme activity is involved in the endothelial dysfunction in angiotensin IIinduced hypertensive rats? Because the renin-angiotensin system is activated in CHF, it is suggested that vascular $\mathrm{NAD}(\mathrm{P}) \mathrm{H}$ oxidase may be a major source of increased $\mathrm{O}_{2}{ }^{-}$ formation and cause the endothelial dysfunction that occurs with the progression of CHF. However, there have been few studies of the involvement of vascular NADPH oxidase in CHF.

It is thought that the 3-hydroxy-3-methylglutaryl-coenzymeA (HMG-CoA) reductase inhibitors (statins), which are widely used as cholesterol-lowering agents, improve endothelial dysfunction in atherosclerosis before significantly reducing the serum cholesterol concentration!10,11 In spontaneously hypertensive rats, atorvastatin partly improved endothelial dysfunction by decreasing the oxidative stress caused by the NAD(P)H oxidase subunit, p22phox!2 However, it has not been fully elucidated whether statins improve endothelial dysfunction by reducing $\mathrm{O}_{2}{ }^{-}$production via inhibition of $\mathrm{NAD}(\mathrm{P}) \mathrm{H}$ oxidase in the setting of normocholesterolemic CHF.

Therefore, we examined (1) whether increased $\mathrm{O}_{2}^{-}$production via the vascular NAD(P)H oxidase is involved in the endothelial dysfunction in tachycardia-induced CHF dogs and (2) whether long-term treatment with pitavastatin, a HMG-CoA reductase inhibitor, improves the endothelial 
dysfunction by inhibiting $\mathrm{NAD}(\mathrm{P}) \mathrm{H}$ oxidase in CHF.

\section{Methods}

\section{Animal Preparation}

All animal experiments were conducted according to the Guidelines for Animal Experimentation of the Animal Research Committee of Shiga University of Medical Science. CHF was induced by rapid right ventricular pacing in young adult beagle dogs, 10-12 months of age, as previously described. ${ }^{13-15}$ After the dogs had recovered from the surgery for at least 14 days, the pacemaker was programmed for 240 beats/min and pacing was continued for 29 days.

\section{Experimental Protocol 1}

Effects of Pitavastatin on Cardiohemodynamics and Endothelium-Dependent/-Independent Vasodilation in CHF The dogs were randomly divided into 3 groups: (1) pitavastatin group $(\mathrm{n}=6)$ received pitavastatin $(0.3 \mathrm{mg} / \mathrm{kg}$ per day, orally once a day), (2) CHF group ( $n=6)$ received only placebo and constituted time controls and (3) normal group $(n=6)$ underwent sham operation without pacing. Pitavastatin is a potent and long-acting HMG-CoA reductase inhibitor $^{16}$ and we selected a dose comparable with that used in humans $(2-4 \mathrm{mg} / \text { day) })^{17}$ Drug treatment commenced on the first day of pacing and continued for 4 weeks. On the 29th day after the initiation of pacing, the pacemaker was deactivated and arterial blood pressure and echocardiographic measurements were subsequently performed with the dogs in the conscious state as described previously $!^{13-15}$ Blood was collected for plasma total cholesterol and neurohumoral assays of plasma angiotensin II concentrations and plasma renin activity (PRA) as previously described.3-15

After the echocardiogram, to evaluate endotheliumdependent and -independent vasodilation, all dogs were given thiopental sodium to provide conscious sedation and allowed to breathe spontaneously during the procedure. A Doppler flow probe was placed on the femoral artery to measure femoral blood flow (FBF) with the VF-1 Pulsed Doppler Flow System (Crystal Biotech Inc, USA) as previously described ${ }^{18}$ A polyethylene tube was inserted into the femoral artery immediately distal to the flow probe for drug infusions, and saline containing heparin $(10 \mathrm{U} / \mathrm{ml})$ was constantly infused at $0.6 \mathrm{ml} / \mathrm{min}$. The partial pressure of oxygen $\left(\mathrm{pO}_{2}\right)$ and $\mathrm{pH}$ in arterial blood were measured with a gas analyzer (Ciba-corning model 280).

After the surgical preparation was completed, indomethacin $(5 \mathrm{mg} / \mathrm{kg})$ was administered intravenously to block the cyclooxygenase pathway. At $30 \mathrm{~min}$ after the administration of indomethacin, the endothelium-dependent vasodilator acetylcholine (ACh) at graded doses $(0.001,0.01,0.1$ and $1 \mu \mathrm{g} \cdot \mathrm{kg}^{-1} \cdot \mathrm{min}^{-1}$ ) was infused (each for 3 min cumulatively, at $0.6 \mathrm{ml} / \mathrm{min}$ ) into the femoral artery. $\mathrm{FBF}$, aortic pressure (AoP) and heart rate (HR) were monitored continuously and recorded. After $15 \mathrm{~min}$, all variables returned to baseline and the endothelium-independent vasodilator nitroglycerin (NTG; $0.1,1$ and $10 \mu \mathrm{g} \cdot \mathrm{kg}^{-1} \cdot \mathrm{min}^{-1}$ ) was then administered. Peak responses of FBF to ACh and NTG were used for analysis.

\section{Experimental Protocol 2}

Effects of L-NMMA on Endothelium-Dependent Vasodilation in CHF Dogs Receiving Pitavastatin To clarify the relationship between endothelium-derived NO and ACh- induced vasodilation in the effect of treatment with pitavastatin, we prepared $4 \mathrm{CHF}$ dogs that received pitavastatin in the first study and we then evaluated the ACh-induced vasodilation before and after the infusion of $\mathrm{NG}^{\mathrm{G}}$-monomethyl-L-arginine (L-NMMA; $1 \mathrm{mg} / \mathrm{kg}$ ) into the femoral artery.

\section{Preparation of Aortic Tissues}

After the in vivo measurements were completed, the dogs were anesthetized with a large dose of pentobarbital sodium and killed by exsanguination from both carotid arteries. The abdominal aortas were isolated and carefully cleaned of excessive adventitial tissue to preserve the endothelium. Segments of aorta $(5 \mathrm{~mm})$ were placed into chilled modified Krebs/HEPES buffer (composition in $\mathrm{mmol} / \mathrm{L}: \mathrm{NaCl} 118, \mathrm{KCl} 4.7, \mathrm{CaCl}_{2} 1.5, \mathrm{MgSO}_{4}$ 1.1, $\mathrm{K}_{2} \mathrm{HPO}_{4} 1.2$, NaHCO 32 25, Na-HEPES 10 and $\mathrm{D}(+)$-glucose $5.5 ; \mathrm{pH} 7.4)$ and some were immediately frozen in liquid nitrogen and stored at $-80^{\circ} \mathrm{C}$ for the quantification of Nox4, gp91phox, p47phox, p22phox and endothelial NO synthase (eNOS) mRNA levels and NOS activity.

\section{Measurement of Ex Vivo Vascular Superoxide Anion $\left(\mathrm{O}_{2}^{-}\right)$ Formation}

The $\mathrm{O}_{2}{ }^{-}$production in the aortic segments was measured using the lucigenin-enhanced chemiluminescence method of Ohara et al with some modifications ${ }^{19}$ Briefly, after preparation, aortic segments were placed in Krebs/HEPES buffer aerated with $95 \% \mathrm{O}_{2}$ and $5 \% \mathrm{CO}_{2}$ and equilibrated for $30 \mathrm{~min}$ at $37^{\circ} \mathrm{C}$. The segments were placed in a polypropylene tube containing $1 \mathrm{ml} \mathrm{Krebs/HEPES} \mathrm{buffer} \mathrm{and}$ lucigenin $(5 \mu \mathrm{mol} / \mathrm{L})$. (It has been shown recently that $5 \mu \mathrm{mol} / \mathrm{L}$ of lucigenin correlates well with electron spin resonance as a quantitative measurement of superoxide production $2^{20}$ ) The tube was placed in an autolumicounter (Nichion, NU-1422E) that reported the relative light units (RLU) emitted, which were integrated over 1 min intervals for $10 \mathrm{~min}$. We found that counts did not significantly increase with longer periods of measurement. To assess $\mathrm{NAD}(\mathrm{P}) \mathrm{H}$ oxidase activity, $\mathrm{NADH}(0.1 \mathrm{mmol} / \mathrm{L})$ or NADPH $(0.1 \mathrm{mmol} / \mathrm{L})$ was added to the Krebs/HEPESlucigenin solution containing the aortic segment, and the $\mathrm{O}_{2}{ }^{-}$concentration was measured. Other segments were preincubated for $30 \mathrm{~min}$ with $1 \mathrm{mmol} / \mathrm{L}$ apocynin (an inhibitor of the activity assembly of the components of $\mathrm{NAD}(\mathrm{P}) \mathrm{H}$ oxidase) or $10 \mu \mathrm{mol} / \mathrm{L}$ diphenyleneiodonium (DPI: an inhibitor of flavin-containing enzymes) to determine the inhibitory effects on NADPH-stimulated $\mathrm{O}_{2}{ }^{-}$ formation. The aortic segments were then dried and their dry weights were determined. Superoxide release is expressed as the RLU above background per milligram of dry tissue.

Quantification of Nox4, gp91phox, p47phox and p22phox (NADPH Oxidase Subunits) and eNOS Gene Expression in the Aorta by Real-Time Polymerase Chain Reaction (PCR)

For the analysis of canine aortic Nox4, gp91phox, p47phox, p22phox and eNOS gene expression, total RNA was extracted from the frozen aorta by the acid guanidinium thiocyanate-chloroform method as previously reported ${ }^{21}$ Real-time PCR was performed with a LightCycler (Roche Molecular Biochemicals, Mannheim, Germany) using a commercially available mix containing Taq DNA polymerase, SYBR-Green I, and deoxyribonucleoside triphosphates (FastStart DNA Master SYBR Green I kit; Roche). Canine 
Table 1 Effects of Pitavastatin on the Hemodynamic Parameters and Blood Analysis

\begin{tabular}{lccc}
\hline \hline & Normal $(n=6)$ & $C H F(n=6)$ & Statin $(n=6)$ \\
\hline$F B F, \mathrm{ml} / \mathrm{min}$ & $47.9 \pm 2.6$ & $33.2 \pm 2.4^{\dagger}$ & $37.1 \pm 1.0^{\dagger}$ \\
$\mathrm{HR}, \mathrm{beats} / \mathrm{min}$ & $123 \pm 9$ & $167 \pm 11^{*}$ & $162 \pm 9^{*}$ \\
Mean $\mathrm{AoP}, \mathrm{mmHg}$ & $137.2 \pm 4.9$ & $109.7 \pm 6.1^{\dagger}$ & $114.3 \pm 5.2^{\dagger}$ \\
$\mathrm{LVDd}, \mathrm{mm}$ & $30.2 \pm 0.4$ & $40.2 \pm 0.4^{\dagger}$ & $38.9 \pm 0.6^{\dagger}$ \\
$\% \mathrm{FS}$ & $29.4 \pm 1.0$ & $10.2 \pm 0.9^{\dagger}$ & $12.8 \pm 0.7^{\dagger}$ \\
$\mathrm{pO}, \mathrm{mmHg}$ & $96.5 \pm 1.9$ & $90.2 \pm 4.4$ & $92.0 \pm 3.2$ \\
$\mathrm{pH}$ & $7.41 \pm 0.02$ & $7.38 \pm 0.03$ & $7.39 \pm 0.02$ \\
Total cholesterol, $\mathrm{mg} / \mathrm{dl}$ & $140 \pm 8$ & $124 \pm 10$ & $119 \pm 7$ \\
Plasma angiotensin II, $\mathrm{pg} / \mathrm{ml}^{\dagger}$ & $39 \pm 8$ & $188 \pm 42^{\dagger}$ & $166 \pm 28^{\dagger}$ \\
Plasma renin activity, $\mathrm{ng} \cdot \mathrm{ml}^{-1} \cdot \mathrm{h}^{-1}$ & $1.1 \pm 0.2$ & $7.2 \pm 1.2^{\dagger}$ & $7.8 \pm 2.0^{\dagger}$ \\
\hline
\end{tabular}

Values are means $\pm S E M$. FBF, femoral blood flow; HR, heart rate; AoP, aortic pressure; $L V D d$, left ventricular end-diastolic dimension; \%FS, \% fractional shortening. ${ }^{*} p<0.05,{ }^{\dagger} p<0.01$ vs normal.

glutaraldehyde-3-phosphate dehydrogenase (GAPDH) and eNOS specific primer pairs were synthesized according to the published data21 Putative canine PCR primers for Nox4, gp91phox, p47phox and p22phox genes were designed based on homology with the highly conserved regions of the coding sequence of the human genes (gene bank: AF254621, BC032720, AF330627, NM000101). The canine Nox4, gp91phox, p47phox and p22phox-specific primer pairs were as follows.

Nox4 S: 5'-TTAAAATAGTAGGA GACTGGAC-3'

Nox4 A: 5'-TCCAATTATCTTCTGTATCCCATC-3'

(PCR product length $416 \mathrm{bp}$ )

gp91phox S: 5'-TGATAAGCAGGAGTTTCAAGATGC-

$3^{3}$

gp91phox A: 5'-GTCTTGAACTCGTTATCCCAGTT-3'

(PCR product length $453 \mathrm{bp}$ )

p47phox S: 5'-AGGAAATGTTTCCTATCGAGGCAG-3' p47phox A: 5'-AGCTCGAGGTCTTCTCGAA GTC-3'

(PCR product length $354 \mathrm{bp}$ )

p22phox S: 5'-TGGCGTCCGGCCTGATCCTC-3'

p22phox A: 5'-GCTCGATGGGGATCCACTGCT-3'

(PCR product length $363 \mathrm{bp}$ ).

Samples were analyzed in 6 independent runs. Serial dilutions of cDNA from the total RNA were performed for each target gene and served as standard curves for quantitative analysis. After the addition of primers (final concentrations $0.5 \mu \mathrm{mol} / \mathrm{L}), \mathrm{MgCl}_{2}(4 \mathrm{mmol} / \mathrm{L})$ and template $\mathrm{DNA}$ to the master mix, 45 cycles of denaturation $\left(95^{\circ} \mathrm{C}, 15 \mathrm{~s}\right)$, annealing $\left(60-65^{\circ} \mathrm{C}, 10 \mathrm{~s}\right)$ and extension $\left(72^{\circ} \mathrm{C}, 10-18 \mathrm{~s}\right)$ were performed. Detection of the fluorescent products was carried out at the end of the $72^{\circ} \mathrm{C}$ extension period. To confirm amplification specificity, the PCR products were subjected to a melting curve analysis and subsequent agarose gel electrophoresis. Data were analyzed with the Light Cycler analysis software as described previously?2

\section{$\mathrm{Ca}^{2+}$-Dependent NOS Activity in the Aorta}

$\mathrm{Ca}^{2+}-$ dependent NOS activity was determined by measuring the conversion of $\left[{ }^{3} \mathrm{H}\right]$-arginine to $\left[{ }^{3} \mathrm{H}\right]$-citrulline using a NOS assay kit (Cayman Chemical, USA). Briefly, frozen aortic segments were suspended in $10 \mathrm{ml} / \mathrm{g}$ ice-cold homogenization buffer $(25 \mathrm{mmol} / \mathrm{L}$ Tris- $\mathrm{HCl}, 1 \mathrm{mmol} / \mathrm{L}$ EDTA, $1 \mathrm{mmol} / \mathrm{L}$ EGTA) and mechanically homogenized with Polytron homogenizer. The homogenates were centrifuged at $5,000 \mathrm{G}$ for $5 \mathrm{~min}$ at $4^{\circ} \mathrm{C}$, after which $10 \mathrm{\mu l}$ supernatant were added to $40 \mu 1$ buffer $(25 \mathrm{mmol} / \mathrm{L}$ Tris- $\mathrm{HCl}$, $3 \mu \mathrm{mol} / \mathrm{L}$ tetrahydrobiopterin, $2 \mu \mathrm{mol} / \mathrm{L}$ flavin adenine dinucleotide, $2 \mu \mathrm{mol} / \mathrm{L}$ flavin adenine mononucleotide, $1 \mathrm{mmol} / \mathrm{L} \mathrm{NADPH}, 0.1 \mu \mathrm{mol} / \mathrm{L}$ calmodulin, and $925 \mathrm{kBq}$
$(25 \mu \mathrm{Ci} / \mathrm{ml}) \mathrm{L}-\left[{ }^{3} \mathrm{H}\right]$-arginine) and incubated for $30 \mathrm{~min}$ at $37^{\circ} \mathrm{C}$ in the presence $(0.75 \mathrm{mmol} / \mathrm{L} \mathrm{CaCl} 2)$ or absence of calcium (ie, nominally calcium free, with $2 \mathrm{mmol} / \mathrm{L}$ EDTA and $2 \mathrm{mmol} / \mathrm{L}$ EGTA). Parallel reactions were analyzed in the absence of NADPH to determine the background signal. Assays were terminated with $400 \mu \mathrm{L}$ stop buffer $\left(50 \mathrm{mmol} / \mathrm{L}\right.$ HEPES, $5 \mathrm{mmol} / \mathrm{L}$ EDTA). $\left[{ }^{3} \mathrm{H}\right]$-citrulline in the supernatant was separated from $\left[{ }^{3} \mathrm{H}\right]$-arginine by cation-exchange chromatography using equilibrated resin (cation-exchange resin) and quantified by liquid-scintillation counting (TRI-CARB1500, Packard Instrument, Meriden, CT, USA). Total NOS and $\mathrm{Ca}^{2+}$-independent activity were each determined by subtracting counts in the absence of NADPH from the counts obtained in the presence or absence of calcium, respectively. $\mathrm{Ca}^{2+}$-dependent activity was calculated as total NOS activity minus $\mathrm{Ca}^{2+}$ independent activity. Citrulline production was normalized to the protein concentration of the homogenates and the protein content was determined using the BCA protein assay kit (Pierce, ID, USA). NOS activity was expressed as picomoles per minute per milligram protein.

\section{Total Cholesterol Analysis}

Blood samples were taken for the determination of the plasma concentration of total cholesterol before the hemodynamic measurements. A commercially available kit was used (Wako Pure Chemicals, Tokyo, Japan).

\section{Statistical Analysis}

Data are expressed as means \pm SEM. Differences among the 3 groups were assessed by ANOVA with the Scheffe's $\mathrm{F}$ test when appropriate. A value of $\mathrm{p}<0.05$ was considered significant.

\section{Results}

As shown in Table 1, after 4 weeks of pacing, the mean AoP decreased and HR increased in the CHF group compared with the normal group and those values did not differ significantly between the CHF group and the pitavastatin group. The left ventricular (LV) end-diastolic dimension increased significantly and LV percent fractional shortening decreased after chronic tachycardia. There were no significant differences in these LV parameters between the CHF and pitavastatin groups. Plasma angiotensin II concentrations and plasma renin activity were significantly increased in both paced groups compared with the normal group. However, those plasma concentrations did not differ significantly between the CHF and pitavastatin groups. 
A

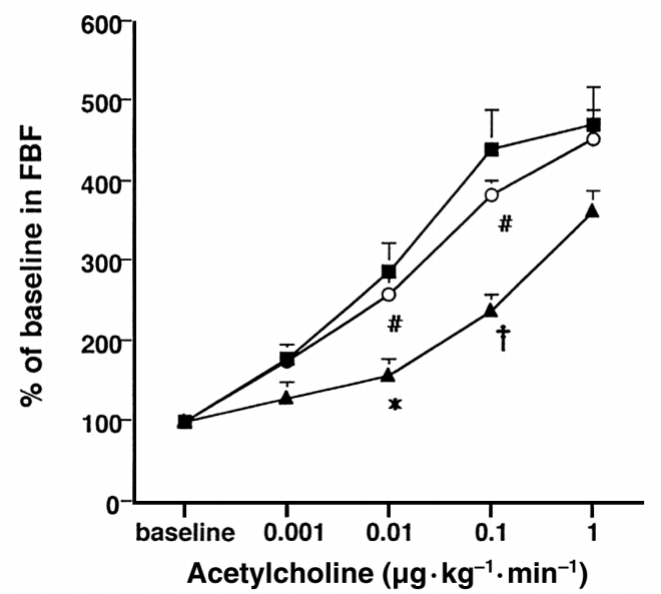

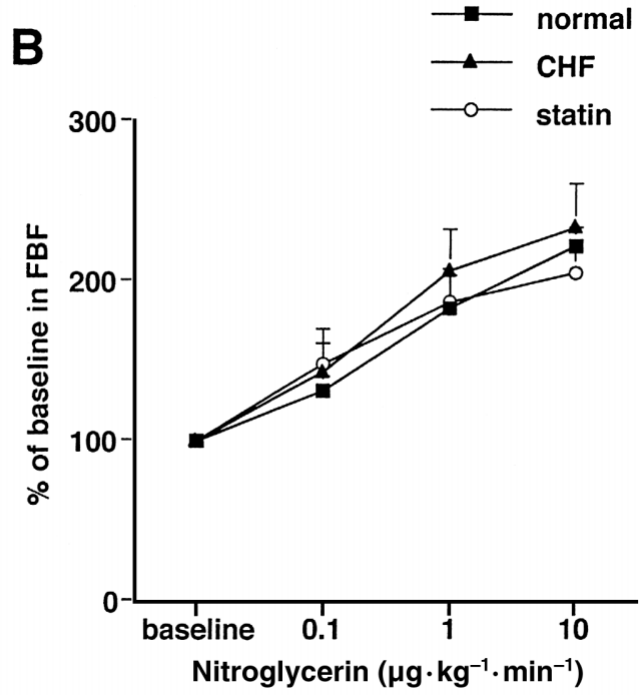

Fig 1. (A) Endothelium-dependent dilation of the femoral circulation evoked by acetylcholine. The percent change in the femoral blood flow (FBF) response to acetylcholine in the normal (closed squares, $n=6$ ), CHF (closed triangles, $n=6$ ), and pitavastatin groups (statin; open circles, $n=6$ ). (B) Endothelium-independent dilation of the femoral circulation evoked by nitroglycerin. The percent change in the FBF responses to nitroglycerin in the normal (closed squares, $n=6$ ), CHF (closed triangles, $\mathrm{n}=6$ ), and pitavastatin groups (statin; open circles, $\mathrm{n}=6$ ). ${ }^{*} \mathrm{p}<0.05,{ }^{\dagger} \mathrm{p}<0.01$ compared with the normal group, ${ }^{\#} \mathrm{p}<0.05$ compared with the CHF group.

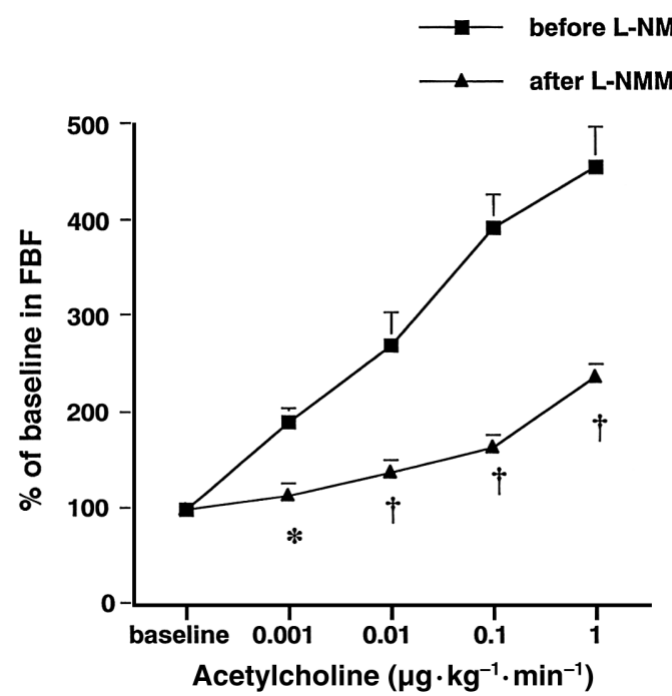

Fig 2. (A) Endothelium-dependent dilation of the femoral circulation evoked by acetylcholine in the pitavastatin treated dogs $(n=4)$. The percent change in the femoral blood flow (FBF) responses to acetylcholine before (closed squares) and after the infusion of LNMMA (closed triangles). ${ }^{*} \mathrm{p}<0.05,{ }^{\dagger} \mathrm{p}<0.01$ vs before the infusion of L-NMMA

There was no significant difference in the total plasma cholesterol concentrations among all groups.

\section{Effect of Pitavastatin on FBF Response to Acetylcholine and Nitroglycerin in $\mathrm{CHF}$}

Baseline FBF was significantly decreased in both the $\mathrm{CHF}$ and pitavastatin groups compared with the normals, as shown in Table 1. The $\mathrm{pO}_{2}$ and $\mathrm{pH}$ in arterial blood did not differ among the 3 groups. The percent ratio of the ACh-induced FBF to baseline FBF was significantly impaired in the CHF group at doses of 0.01 and $0.1 \mu \mathrm{g} \cdot \mathrm{kg}^{-1}$. $\mathrm{min}^{-1}$, compared with the normal group (Fig 1A), but the

\section{Superoxide production}

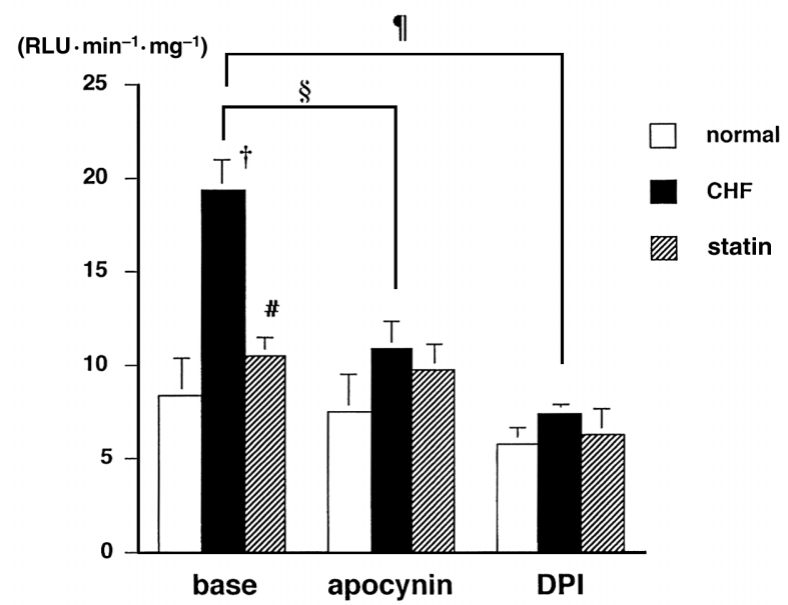

Fig 3. Basal $\mathrm{O}_{2}-$ levels measured by lucigenin-enhanced chemiluminescence in aortic segments from the normal (open bars, $n=6$ ), CHF (closed bars, $n=6$ ), and pitavastatin groups (statin; cross-hatched bars, $n=6$ ) in the absence or presence of apocynin or DPI. ${ }^{\dagger} p<0.01$ compared with the normal group, ${ }^{\#} \mathrm{p}<0.05$ compared with the CHF group, $\S_{\mathrm{p}}<0.05$, I $\mathrm{p}<0.01$ compared with baseline.

ratio was significantly enhanced by pitavastatin when compared with the CHF group (Fig 1A). The percent ratio of the NTG-induced FBF to baseline FBF did not differ among the 3 groups (Fig 1B). As shown in Fig 2, the infusion of L-NMMA markedly reduced the ACh-induced increase in $\mathrm{FBF}$ in the $\mathrm{CHF}$ dogs receiving pitavastatin.

\section{Effects of Pitavastatin on Vascular $\mathrm{O}_{2}-$ Formation and $\mathrm{NAD}(\mathrm{P}) \mathrm{H}$ Oxidase Activity in $\mathrm{CHF}$}

As shown in Fig 3, $\mathrm{O}_{2}^{-}$formation in the aorta was greater in the CHF group than in the normal group, and pitavastatin suppressed $\mathrm{O}_{2}-$ formation to normal levels. Apocynin 
A NADH oxidase activity

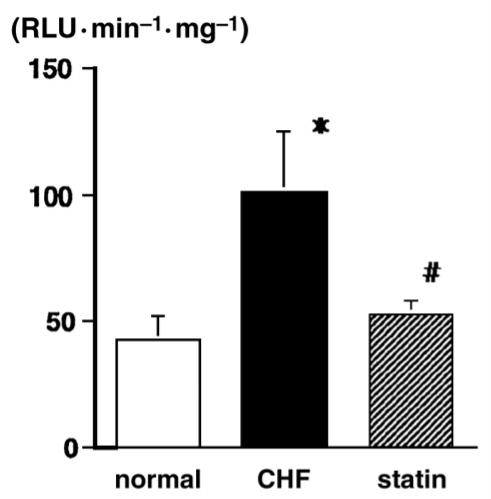

\section{B NADPH oxidase activity}

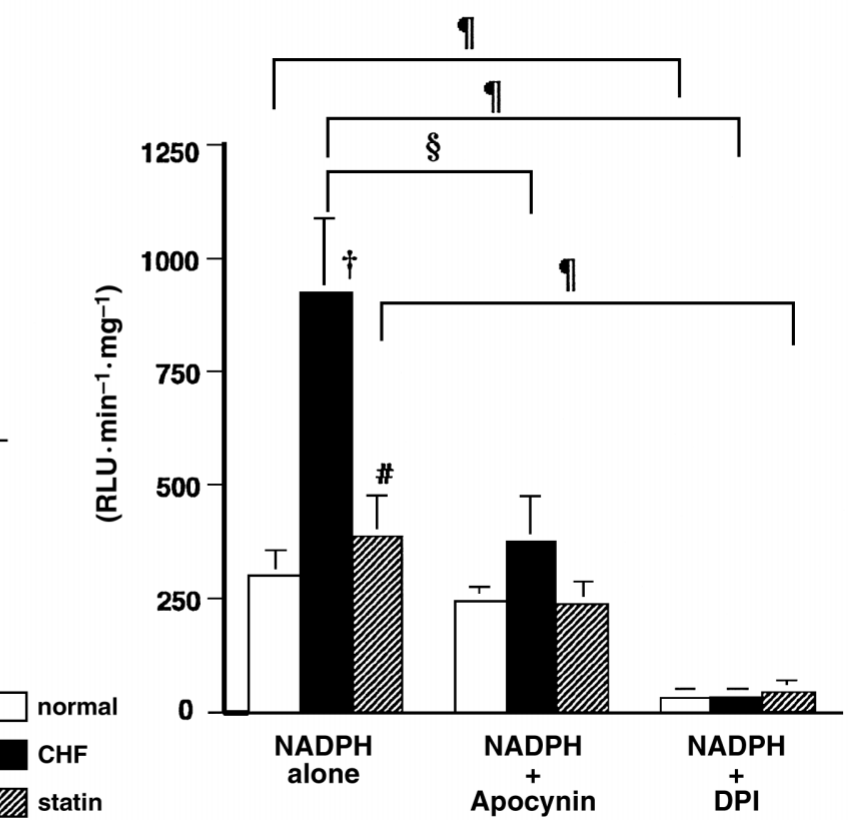

Fig 4. (A) NADH oxidase activity in aortic segments of the normal (open bars, $n=6$ ), CHF (closed bars, $n=6$ ), and pitavastatin groups (statin; cross-hatched bars, $n=6$ ). (B) NADPH oxidase activity in aortic segments from the normal (open bars, $n=6$ ), CHF (closed bars, $n=6$ ), and pitavastatin groups (statin; cross-hatched bars, $n=6$ ) in the absence or presence of apocynin or DPI. ${ }^{*} \mathrm{p}<0.05,{ }^{\dagger} \mathrm{p}<0.01$ compared with the normal group, ${ }^{*} \mathrm{p}<0.05$ compared with the CHF group, ${ }^{\S} \mathrm{p}<0.05$, "I $<0.01$ compared with baseline.

and DPI treatment in the CHF group also significantly decreased $\mathrm{O}_{2}{ }^{-}$formation in the aorta to the normal levels. As shown in Fig 4, NADH and NADPH oxidase activities in the aorta were also greater in the CHF group than in the normal group and pitavastatin decreased both those activities to normal levels. Apocynin treatment normalized NADPH oxidase activity in the aorta in the CHF group whereas DPI treatment significantly decreased NADPH oxidase activity in the aorta in all groups.

Effect of Pitavastatin on Vascular Nox4, gp91phox, p47phox and p22phox Expression in $\mathrm{CHF}$

As shown in Figs 5 and 6, the mRNA levels of Nox4 and p47phox in the aorta were increased in the CHF group compared with the normal group and pitavastatin significantly suppressed the levels of expression. However, the mRNA levels of gp91phox and p22phox in the aorta did not significantly differ among all groups.

\section{Effects of Pitavastatin on Vascular eNOS Expression and $\mathrm{Ca}^{2+}-$ Dependent NOS Activity in $\mathrm{CHF}$}

As shown in Fig 7, the mRNA levels of eNOS and $\mathrm{Ca}^{2+}$ dependent NOS activity in the aorta did not significantly differ between the normal and the CHF groups; however, pitavastatin significantly increased aortic eNOS gene expression and aortic $\mathrm{Ca}^{2+}$-dependent NOS activity compared with those groups.

\section{Discussion}

In the present study, endothelium-dependent vasodilation in dogs with tachycardia-induced CHF was attenuated via an increase in the formation of vascular $\mathrm{NAD}(\mathrm{P}) \mathrm{H}$ oxidase-derived $\mathrm{O}_{2}{ }^{-}$, accompanied by upregulation of the expression of Nox4 and p47phox, which are NADPH oxidase subunits. Pitavastatin, a HMG-CoA reductase inhibitor, did not affect cardiac systolic function, but it does have antioxidant properties associated with suppression of $\mathrm{NAD}(\mathrm{P}) \mathrm{H}$ oxidase activity and the expression of vascular Nox4 and p47phox, resulting in improvement of endothelial dysfunction in normocholesterolemic CHF. In addition, pitavastatin increased both vascular eNOS expression and activity. In our experimental design, the effects of pitavastatin on vascular $\mathrm{O}_{2}{ }^{-}$production and eNOS expression were found to be independent of plasma cholesterol concentrations.

Vascular Oxidative Stress and NAD $(P) H$ Oxidase in CHF

The involvement of $\mathrm{NO}$ in endothelial dysfunction is well known, but another contributing mechanism of the endothelial dysfunction observed in CHF is the increased production of reactive oxygen species. ${ }^{4-623}$ There have been previous reports that an oxygen free radical scavenger, tiron, inhibited $\mathrm{O}_{2}-$ formation and improved coronary endothelial dysfunction and coronary flow reserve by increasing NO bioactivity in $\mathrm{CHF}^{6}, 6,23$ however, it is unclear exactly what is the major source of the increased production of reactive oxygen species in the peripheral vessels in CHF. NAD(P)H oxidase is an inducible electron transport system and represents the most important source of $\mathrm{O}_{2}^{-}$production in vascular cells. ${ }^{7}, \mathrm{NAD}(\mathrm{P}) \mathrm{H}$ oxidase consists of a membrane-integrated b-type cytochrome, cytochrome b558, which is composed of 91 and $22 \mathrm{kDa}$ subunits (gp91phox and p22phox, respectively), and at least 3 cytosolic proteins (p47phox, p67phox and p21rac). Although the catalytic subunit of vascular $\mathrm{NAD}(\mathrm{P}) \mathrm{H}$ oxidase has been largely unknown for a long period of time, a family of gp91phox-like proteins, termed the non- 


\section{A $\frac{\text { Nox4 mRNA }}{\text { GAPDH mRNA }}$}

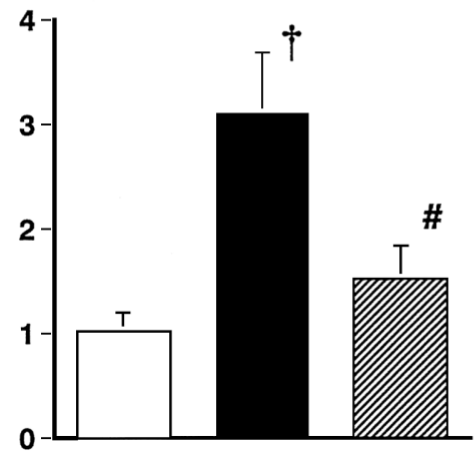

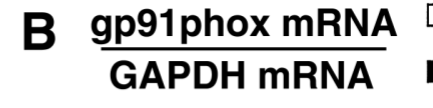

normal

CHF

叉statin

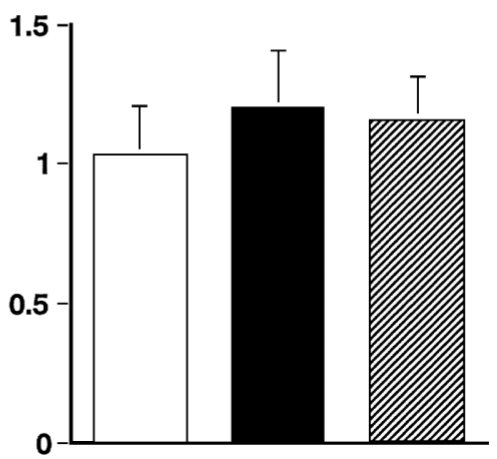

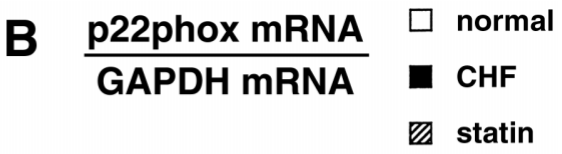

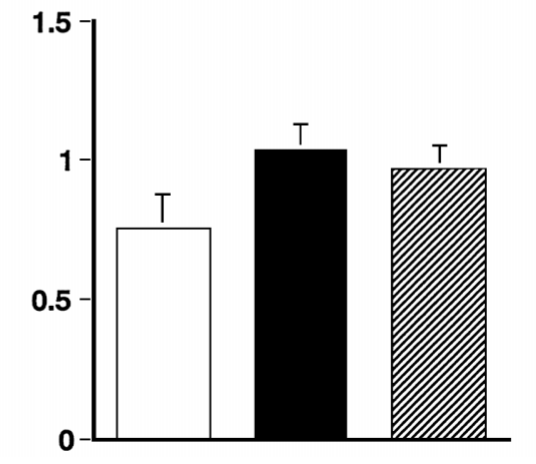

Fig 5. (A) Ratio of the mRNA expression of Nox4 to GAPDH in the aorta of the normal (open bars, $n=5$ ), CHF (closed bars, $\mathrm{n}=5$ ) and pitavastatin groups (statin; crosshatched bars, $n=5$ ). (B) Ratio of the mRNA expression of gp91phox to GAPDH in the aorta of the normal (open bars, $n=5$ ), CHF (closed bars, $\mathrm{n}=5$ ) and pitavastatin groups (statin; cross-hatched bars, $n=5$ ). ${ }^{\dagger}<0.01$ compared with the normal group, ${ }^{\#} \mathrm{p}<0.05$ compared with the CHF group.
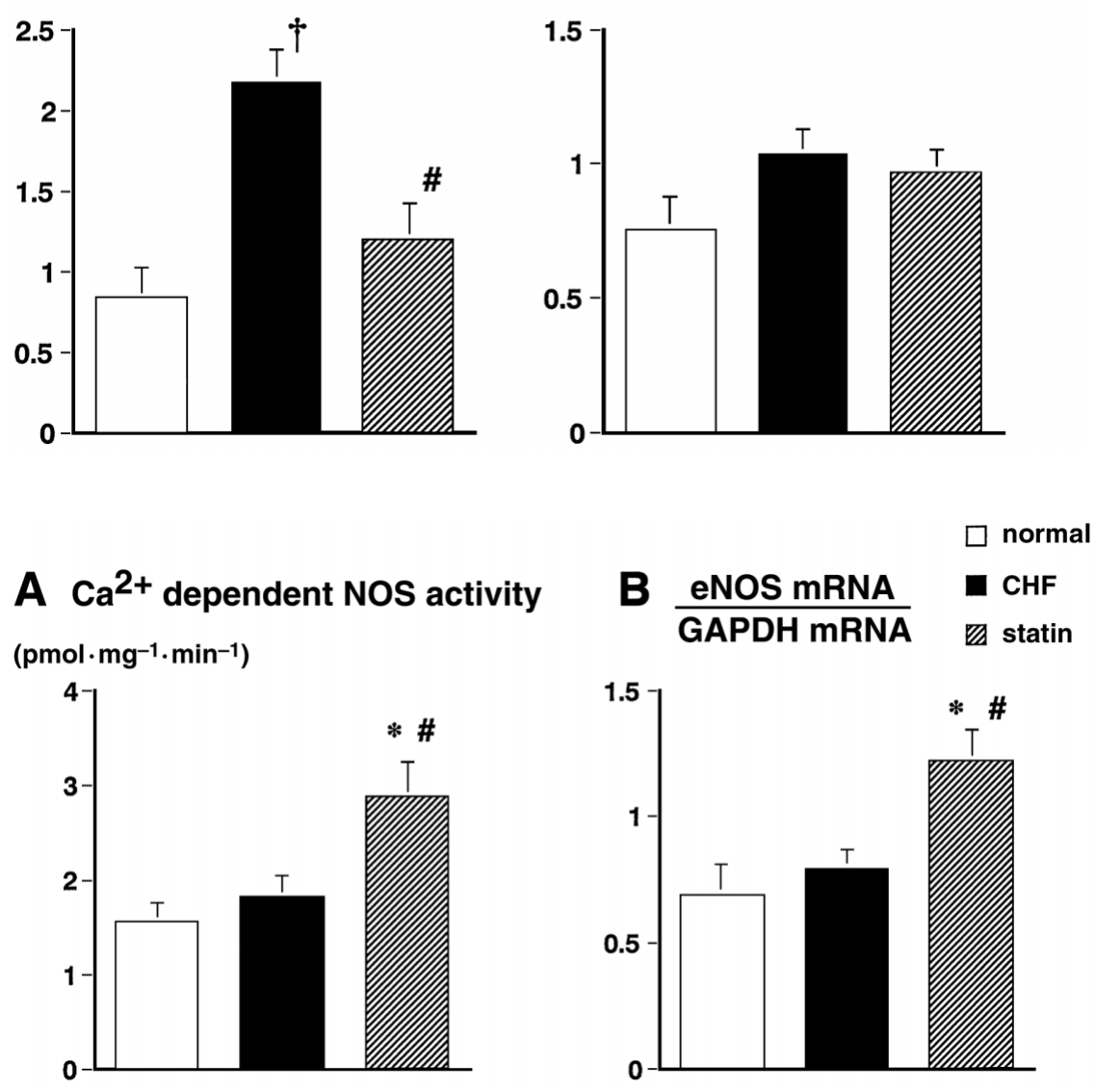

Fig 6. (A) Ratio of the mRNA expression of p47phox to GAPDH in the aorta of the normal (open bars, $n=5$ ), CHF (closed bars, $\mathrm{n}=5$ ) and pitavastatin groups (statin; crosshatched bars, $n=5$ ). (B) Ratio of the mRNA expression of p22phox to GAPDH in the aorta of the normal (open bars, $n=5$ ), CHF (closed bars, $n=5$ ) and pitavastatin groups (statin; cross-hatched bars, $\mathrm{n}=5$ ). ${ }^{\dagger} \mathrm{p}<0.01$ compared with the normal group, ${ }^{\#} \mathrm{p}<0.05$ compared with the CHF group.

Fig 7. (A) Changes in $\mathrm{Ca}^{2+}$-dependent
NOS activity in the aorta of the normal
(open bars, $\mathrm{n}=6$ ), CHF (closed bars, $\mathrm{n}=6$ )
and pitavastatin groups (statin; cross-
hatched bars, $\mathrm{n}=6$ ). (B) Ratio of the
mRNA expression of eNOS to GAPDH in
the aorta of the normal (open bars, $n=5$ ),
CHF (closed bars, $n=5$ ) and pitavastatin
groups (statin; cross-hatched bars, $n=5$ ).
* $<<0.05$ compared with the normal group,
$\# p<0.05$ compared with the CHF group.

phagocytic NAD(P)H oxidases (Nox-1, -3, -4, -5), has been identified recently ${ }^{24}$ and Nox4 in particular is the predominant vascular isoform. ${ }^{25}$ In the present study, we demonstrated that vascular $\mathrm{O}_{2}-$ production assessed by lucigenin chemiluminescence was significantly elevated, and endothelium-dependent vasorelaxation was attenuated, in dogs with $\mathrm{CHF}$ and normocholesterolemia, despite no changes in either vascular eNOS expression or activity. We also observed that vascular $\mathrm{NAD}(\mathrm{P}) \mathrm{H}$-oxidase activity was significantly elevated in the CHF dogs and the expression of vascular Nox4 and p47phox was significantly increased whereas that of vascular gp91phox and p22phox was unchanged. In $\mathrm{CHF}$ rats with myocardial infarction, aortic superoxide anion generation was significantly enhanced, accompanied by an elevation of the expression of the NAD(P)H oxidase subunit p47phox protein26 Nox4 serves as a catalytic NAD(P)H oxidase subunit in nonphagocytic cells in contrast to the expression of gp91phox which is 
mainly associated with increased macrophage content of the arteries 25 Different localization and cell types among each $\mathrm{NAD}(\mathrm{P}) \mathrm{H}$ oxidase subunit may be attributed to the disparities in the altered expression of the enzyme subunits in CHF. Furthermore, apocynin, which is a specific inhibitor of $\mathrm{NAD}(\mathrm{P}) \mathrm{H}$ oxidase that impedes the assembly of the p47phox subunit with the membrane complex, ${ }^{27}$ inhibited vascular $\mathrm{O}_{2}{ }^{-}$production and NADPH oxidase activity in $\mathrm{CHF}$, but had no effect in normal dogs. DPI, an inhibitor of flavin-containing enzymes, also exerted similar effects to apocynin on vascular $\mathrm{O}_{2}^{-}$production in $\mathrm{CHF}$, inhibiting not only NADPH oxidase but also various sources of reactive oxygen species such as xanthine oxidase, nitric oxide

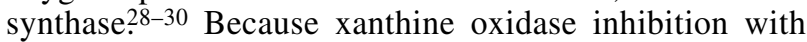
allopurinol attenuates allantoin, a marker of oxygen free radical generation, and improves peripheral vasodilator capacity in hyperuricemic patients with $\mathrm{CHF}$, xanthine oxidase may, in part, contribute to the endothelial dysfunction observed in CHF via upregulation of oxidative stress 31 Furthermore, when tetrahydrobiopterin, which is a critical cofactor for eNOS, is decreased, eNOS becomes uncoupled from the cofactor and produces $\mathrm{O}_{2}{ }^{-}$instead of $\mathrm{NO}^{32}$ In addition, eNOS uncoupling in platelets from patients with $\mathrm{CHF}$ has been associated with decreased platelet-derived NO production and impaired endothelium-dependent vasodilation 33 However, in the present study, the changes in vascular $\mathrm{O}_{2}-$ production after apocynin treatment were similar to those observed after DPI treatment. Moreover, the elevated NADPH oxidase activity in CHF was inhibited to almost normal levels by apocynin. Therefore, the involvement of other vascular $\mathrm{O}_{2}-$ generating systems including xanthine oxidase and eNOS may have been minimal in the present model.

\section{Chronic Effects of Pitavastatin on Endothelial Dysfunction in $\mathrm{CHF}$}

Statins improve endothelial dysfunction in atherosclerosis before there is a significant reduction in serum cholesterol concentration, suggesting a pleiotropic effect of statins beyond the reduction in plasma cholesterol!10,11 One important action of the statins is their ability to suppress the production of oxygen-derived free radicals 34,35 In aortic segments from spontaneous hypertensive rats, atorvastatin inhibited the translocation of rac1 from the cytosol to the cell membrane, which is required for the activation of $\mathrm{NAD}(\mathrm{P}) \mathrm{H}$ oxidase, and the agent also reduced the gene expression of the vascular $\mathrm{NAD}(\mathrm{P}) \mathrm{H}$ oxidase subunits, resulting in decreased $\mathrm{O}_{2}{ }^{-}$production ${ }^{34}$ Statins can produce various beneficial antioxidant effects through their direct inhibition of $\mathrm{NAD}(\mathrm{P}) \mathrm{H}$ oxidase, beyond the action of blocking the synthesis of cholesterol. In the present study, we demonstrated that pitavastatin improved the impaired endothelium-dependent vasodilation in CHF associated with the suppression of $\mathrm{NAD}(\mathrm{P}) \mathrm{H}$ oxidase activities and vascular $\mathrm{O}_{2}-$ production. The statin also suppressed increased the gene expression of Nox 4 and p47phox. Both apocynin and DPI completely suppressed $\mathrm{O}_{2}^{-}$formation to normal levels in the vessels from CHF dogs, but neither compound affected the vascular $\mathrm{O}_{2}-$ levels after treatment with pitavastatin. In contrast to atherosclerosis, lipid disorders were not involved in our pathological setting; however, because the activation of $\mathrm{NAD}(\mathrm{P}) \mathrm{H}$ oxidase is involved in the endothelial dysfunction in the present CHF animal model, we assume that statins definitely improve endothelial dysfunction in $\mathrm{CHF}$, in part by inhibiting the NADPH oxidase pathway.

In $\mathrm{CHF}$, the vascular expression of eNOS is contradictory, as increased, decreased and unaltered. In the present study, the levels of eNOS mRNA and $\mathrm{Ca}^{2+}$-dependent NOS activity in the aorta were not altered after the induction of $\mathrm{CHF}$, so the arterial endothelial dysfunction in our $\mathrm{CHF}$ model is not likely to be the result of blunted eNOS responses. However, pitavastatin upregulated vascular eNOS expression and increased $\mathrm{Ca}^{2+}$-dependent NOS activity in the CHF group compared with both the normal control and CHF groups. Indeed, statins upregulated eNOS expression by inhibiting geranylgeranylation of Rho GTPase in the endothelial cells of the human saphenous vein. 36 In addition, we confirmed the relationship between NO and ACh-induced vasodilation in the effect of pitavastatin therapy, using L-NMMA. The improvement was inhibited by L-NMMA, indicating that the beneficial effect of the statin was mediated through increased vascular NO bioavailability. Thus, both enhanced NO production and suppression of NO destruction may be involved in the improvement of endothelial dysfunction during treatment with statins.

$\mathrm{NAD}(\mathrm{P}) \mathrm{H}$ oxidases are activated by mechanical stress, hormones and cytokines and, in particular, angiotensin II is an important activating stimulus for vascular $\mathrm{NAD}(\mathrm{P}) \mathrm{H}$ oxidase 24 In angiotensin II-induced hypertensive rats, vascular $\mathrm{O}_{2}{ }^{-}$production via $\mathrm{NAD}(\mathrm{P}) \mathrm{H}$ oxidase activation increased and the impaired vascular relaxation caused by ACh was corrected with superoxide dismutase? Because $\mathrm{CHF}$ is accompanied by activation of the renin-angiotensin system in both plasma and cardiovascular tissues, that system appears to be responsible for increased $\mathrm{NAD}(\mathrm{P}) \mathrm{H}$ oxidase activity in the vasculature in CHF. We observed that plasma renin activity and angiotensin II concentrations significantly increased in CHF dogs and that pitavastatin suppressed $\mathrm{NAD}(\mathrm{P}) \mathrm{H}$ oxidase. However, the statin did not change plasma angiotensin II concentrations in comparison with the CHF dogs. Therefore, the inhibitory effect of pitavastatin on NADPH oxidase is not likely to be from suppressing the circulating renin-angiotensin system.

Some studies have reported that statins improve cardiac remodeling and function in $\mathrm{CHF}, 37,38$ and there is a possibility that the cardiohemodynamic amelioration by statins may subsequently improve endothelial dysfunction in CHF. However, in the present study, pitavastatin did not improve cardiac systolic function in CHF.

\section{Study Limitations}

First, we evaluated endothelial function by measuring the ACh-induced increase in FBF, which is involved in not only conduit but also resistance arterial endothelial function. However, we examined eNOS expression and $\mathrm{O}_{2}{ }^{-}$ production in only the conduit artery. Additional future studies will be needed in order to evaluate the changes in eNOS expression and $\mathrm{O}_{2}^{-}$production in the resistance artery. Second, another contributing mechanism to the endothelial dysfunction in CHF may be decreased antioxidant defenses. We did not assess the effect of pitavastatin on vascular antioxidant activities in CHF; however, it has been reported that the activities of various endogenous antioxidants, such as superoxide dismutase, catalase and glutathione peroxidase in the failing heart, are not decreased in the tachycardia-induced CHF model ${ }^{39}$ Further studies are also needed to clarify whether or not endogenous antioxidants contribute to endothelial dysfunction under 
chronic treatment of pitavastatin in CHF. Third, statins have direct anti-inflammatory properties and reduce macrophage proliferation and activation in the vasculature. ${ }^{40}$ Because the expression of gp91phox mRNA was not increased in the present study, we considered that infiltrating macrophages did not contribute to the activated NADPH oxidase in the vessels. However, we did not examine this by immunohistochemistry. Additional future studies will, thus, be needed in order to evaluate the effect of statins on the vascular anti-inflammatory reaction in CHF.

\section{Clinical Implications}

Statins are known to reduce the morbidity and mortality in patients with coronary artery disease by lowering serum cholesterol concentrations. ${ }^{4}$ However, their therapeutic effects in non-ischemic heart failure still remain unclear. In the present study, pitavastatin improved peripheral endothelial dysfunction in CHF, so we anticipate an improvement in both exercise capacity and tissue perfusion in patients with CHF. Therefore, statins may become a widely used strategy in the treatment of $\mathrm{CHF}$, independent of their cholesterol lowering effect.

\section{Conclusions}

The present findings suggest that increased $\mathrm{O}_{2}^{-}$production via activated vascular NAD $(\mathrm{P}) \mathrm{H}$ oxidase contributes to the endothelial dysfunction in tachycardia-induced $\mathrm{CHF}$ dogs. Pitavastatin improved the endothelial dysfunction by modulating the $\mathrm{NO} / \mathrm{O}_{2}{ }^{-}$balance via both significant reduction of $\mathrm{NAD}(\mathrm{P}) \mathrm{H}$ oxidase derived $\mathrm{O}_{2}{ }^{-}$formation and upregulation of eNOS expression.

\section{Acknowledgments}

We wish to thank Ikuko Matsumoto, Akiko Yoshii (Department of Cardiovascular and Respiratory Medicine, Shiga University of Medical Science, Shiga, Japan) and Masafumi Suzaki (Central Research Laboratory, Shiga University of Medical Science, Shiga, Japan) for their technical assistance. We are also grateful to the Pharmaceutical Division of Kowa Company Ltd, Japan, for supplying the pitavastatin. This study was supported by a grant-in-aid for Scientific Research $(C)$ from the Ministry of Education, Culture, Sports Science and Technology of Japan.

\section{References}

1. Kubo SH, Rector TS, Bank AJ, Williams RE, Heifetz SM. Endothelium-dependent vasodilation is attenuated in patients with heart failure. Circulation 1991; 84: 1589-1596.

2. Drexler H, Hayoz D, Munzel T, Hornig B, Just H, Brunner HR, et al. Endothelial function in chronic congestive heart failure. $\mathrm{Am} J$ Cardiol 1992; 69: 1596-1601.

3. Egashira K. Clinical importance of endothelial function in atherosclerosis and ischemic heart disease. Circ J 2002; 66: 529-533.

4. Bauersachs J, Bouloumie A, Fraccarollo D, Hu K, Busse R, Ertl G. Endothelial dysfunction in chronic myocardial infarction despite increased vascular endothelial nitric oxide synthase and soluble guanylate cyclase expression: Role of enhanced vascular superoxide production. Circulation 1999; 100: 292-298.

5. Hornig B, Arakawa N, Kohler C, Drexler H. Vitamin C improves endothelial function of conduit arteries in patients with chronic heart failure. Circulation 1998; 97: 363-368.

6. Arimura K, Egashira K, Nakamura R, Ide T, Tsutsui H, Shimokawa $\mathrm{H}$, et al. Increased inactivation of nitric oxide is involved in coronary endothelial dysfunction in heart failure. Am J Physiol Heart Circ Physiol 2001; 280: H68-H75.

7. Griendling KK, Minieri CA, Ollerenshaw JD, Alexander RW. Angiotensin II stimulates NADH and NADPH oxidase activity in cultured vascular smooth muscle cells. Circ Res 1994; 74: $1141-$ 1148 .

8. Mohazzab KM, Kaminski PM, Wolin MS. NADH oxidoreductase is major source of superoxide anion in bovine coronary artery endothelium. Am J Physiol 1994; 266: H2568 - H2572.

9. Rajogopalan S, Kurz S, Munzel T, Tarpey M, Freeman B, Griending $\mathrm{KK}$, et al. Angiotensin II-mediated hypertension in the rat increases vascular superoxide production via membrane NADH/NADPH oxidase activation. J Clin Invest 1996; 97: 1916-1923.

10. O'Driscoll G, Green D, Taylor RR. Simvastatin, an HMG-coenzyme A reductase inhibitor, improves endothelial function within 1 month. Circulation 1997; 95: 1126-1131.

11. Tsunekawa T, Hayashi T, Kano H, Sumi D, Matsui H, Thakur N, et al. Cerivastatin, a hydroxymethylglutaryl coenzyme A reductase inhibitor, improves endothelial function in elderly diabetic patients with 3 days. Circulation 2001; 104: 376-379.

12. Wassmann S, Laufs U, Baumer AT, Muller K, Ahlobory K, Linz W, et al. HMG-CoA reductase inhibitors improve endothelial dysfunction in normocholesterolemic hypertension via reduced production of reactive oxygen species. Hypertension 2001; 37: 1450-1457.

13. Wada A, Tsutamoto T, Matsuda Y, Kinoshita M. Cardiorenal and neurohumoral effects of endogenous atrial natriuretic peptide in dogs with severe congestive heart failure using a specific antagonist for guanylate cyclase-coupled receptors. Circulation 1994; 89: $2232-$ 2240.

14. Wada A, Tsutamoto T, Ohnishi M, Sawaki M, Fukai D, Maeda Y, et al. Effects of a specific endothelin-converting enzyme inhibitor on cardiac, renal, and neurohumoral functions in congestive heart failure: Comparison of effects with those of endothelin A receptor antagonism. Circulation 1999; 99: 570-577.

15. Fukai D, Wada A, Tsutamoto T, Kinoshita M. Short-term and longterm inhibition of endogenous atrial natriuretic peptide in dogs with early stage heart failure. Jpn Circ J 1998; 62: 604-610.

16. Aoki T, Nishimura H, Nakagawa S, Kojima J, Suzuki H, Tamaki T, et al. Pharmacological profile of a novel synthetic inhibitor of 3hydroxy-3-methylglutaryl-coenzyme A reductase. Arzneimittelforsehung 1997; 47: 904-909.

17. Noji Y, Higashikata T, Inazu A, Nohara A, Ueda K, Miyamoto S, et al. Long-term treatment with pitavastatin (NK104), a new HMGCoA reductase inhibitor, of patients with heterozygous familial hypercholesterolemia. Atherosclerosis 2002; 163: 157-164.

18. Nakae I, Takahashi M, Kinoshita T, Matsumoto T, Kinoshita M. The effect of S-Nitrosocaptopril on canine coronary circulation. $J$ Pharmacol Exp Ther 1995; 275: 1247-1253.

19. Ohara Y, Peterson TE, Harrison DG. Hypercholesterolemia increases endothelial superoxide anion production. J Clin Invest 1993; 91: $2546-2551$.

20. Li Y, Zhu H, Kuppusamy P, Roubaud V, Zweier JL, Trush MA. Validation of lucigenin (bis-N-methylacridinium) as a chemilumigenic probe for detecting superoxide anion radical production by enzymatic and cellular systems. J Biol Chem 1998; 273: 2015-2023.

21. Fujii M, Wada A, Tsutamoto T, Ohnishi M, Isono T, Kinoshita M. Bradykinin contributes to LV diastolic function under chronic ACE inhibition in heart failure. Hypertension 2002; 39: 952-957.

22. Morrison TB, Weis JJ, Wittwer CT. Quantification of low-copy transcripts by continuous SYBR Green I monitoring during amplification. Biotechniques 1998; 24: 954-958, 960-962.

23. Nakamura R, Egashira K, Arimura K, Machida Y, Ide T, Tsutsui H, et al. Increased inactivation of nitric oxide is involved in impaired coronary flow reserve in heart failure. Am J Physiol Heart Circ Physiol 2001; 281: H2619-H2625.

24. Cai H, Griendling KK, Harrison DG. The vascular NAD (P)H oxidases as therapeutic targets in cardiovascular diseases. Trends Pharmacol Sci 2003; 24: 471-478.

25. Sorescu D, Weiss D, Lassègue B, Clempus RE, Szöcs K, Sorescu GP, et al. Superoxide production and expression of Nox family proteins in human atherosclerosis. Circulation 2002; 105: 14291435 .

26. Widder J, Behr T, Fraccarollo D, Hu K, Galuppo P, Tas P, et al. Vascular endothelial dysfunction and superoxide anion production in heart failure are p38 MAP kinase-dependent. Cardiovasc Res 2004; 63: $161-167$.

27. Meyer JW, Holland JA, Ziegler LM, Chang MM, Beebe G, Schmit ME. Identification of a function leukocyte-type NADPH oxidase in human endothelial cells: A potential atherogenic source of reactive oxygen species. Endothelium 1990; 7: 11-22.

28. Cross AR, Jones OT. The effect of the inhibitor diphenyleneiodonium on the superoxide generating system of neutrophils: Specific labeling of a component polypeptide of the oxidase. Biochem J 1986; 237: $111-116$

29. Sanders SA, Eisenthal R, Harrison R. NADH oxidase activity of human xanthine oxidoreductase-generation of superoxide anion. Eur J Biochem 1997; 245: 541-548. 
30. Stuehr DJ, Fasehun OA, Kwon NS, Gross SS, Gonzalez JA, Levi R, et al. Inhibition of macrophage and endothelial cell nitric oxide synthase by diphenyleneiodonium and its analogs. FASEB J 1991; 5: $98-103$.

31. Doehner W, Schoene N, Rauchhaus M, Leyva-Leon F, Pavitt D, Reaveley D, et al. Effects of xanthine oxidase inhibition with allopurinol on endothelial function and peripheral blood flow in hyperuricemic patients with chronic heart failure: Results from 2 placebocontrolled studies. Circulation 2002; 105: 2619-2624.

32. Vasquez-Vivar J, Kalyanaraman B, Martasek P, Hogg N, Masters BSS, Karoui H, et al. Superoxide generation by endothelial nitric oxide synthase: The influence of cofactors. Proc Natl Acad Sci USA 1998; 95: 9220-9225.

33. Dixon LJ, Morgan DR, Hughes SM, McGrath LT, El-Sherbeeny NA, Plumb RD, et al. Functional consequences of endothelial nitric oxide synthase uncoupling in congestive cardiac failure. Circulation 2003; 107: $1725-1728$.

34. Wassmann S, Laufs U, Muller K, Konkol C, Ahlbory K, Baumer AT, et al. Cellular antioxidant effects of atorvastatin in vitro and in vivo. Arterioscler Thromb Vasc Biol 2002; 22: 300-305.

35. Tamura A, Watanabe T, Nasu M. Effects of atorvastatin and pravastatin on malondialdehyde-modified LDL in hypercholesterolemic patients. Circ J 2003; 67: 816-820.
36. Laufs U, La Fata V, Plutzky J, Liao JK. Upregulation of endothelial nitric oxide synthase by HMG CoA reductase inhibitors. Circulation 1998; 97: 1129-1135.

37. Hayashidani S, Tsutsui H, Shiomi T, Suematsu N, Kinugawa S, Ide $\mathrm{T}$, et al. Fluvastatin, a 3-hydroxy-3-methylglutaryl coenzyme A reductase inhibitor, attenuates left ventricular remodeling and failure after experimental myocardial infarction. Circulation 2002; 105: $868-873$.

38. Node K, Fujita M, Kitakaze M, Hori M, Liao JK. Short-term statin therapy improves cardiac function and symptoms in patients with idiopathic dilated cardiomyopathy. Circulation 2003; 108: 839-843.

39. Tsutsui H, Ide T, Hayashidani S, Suematsu N, Utsumi H, Nakamura $\mathrm{R}$, et al. Greater susceptibility of failing cardiac myocytes to oxygen free radical-mediated injury. Cardiovasc Res 2001; 49: 103-109.

40. Ni W, Egashira K, Kataoka C, Kitamoto S, Koyanagi M, Inoue S, et al. Antiinflammatory and antiarteriosclerotic actions of HMG-CoA reductase inhibitors in a rat model of chronic inhibition of nitric oxide synthase. Circ Res 2001; 89: 415-421.

41. Scandinavian Simvastatin Survival Study Group. Randomised trial of cholesterol lowering in 4444 patients with coronary heart disease: The Scandinavian Simvastatin Survival Study (4S). Lancet 1994; 344: $1383-1389$. 